\title{
Conciliating ventilation requirements and geomechanical requirements for deep mining
}

\author{
D Thibodeau Stantec, Canada \\ J Jodouin Stantec, Canada
}

\begin{abstract}
As mines go deeper, managing heat due to the geothermal gradient, auto compression and the large diesel equipment used to achieve production is a constant battle. Ventilation requirement to cool down the work place is in constant opposition to the geomechanical constraints related to increased stress level, seismicity and rock mass failure. To minimise the energy used to push air through the deep workplaces of a mine, ventilation requires large conduits to keep friction and turbulence to a minimum and avoid undue warming of the fresh air before it reaches its destination. On the contrary, smaller openings at depth allows mines better mitigation of geomechanical risk providing improved long term stability and allowing permanent infrastructures to be closer to the ore body. Ventilation and geomechanical considerations, being the two pillars of deep mine design, are opposed to each other. This paper demonstrates how ventilation requirements and geomechanical requirements can be conciliated for deep mine design to ensure safe production.
\end{abstract}

This paper describes the basic ventilation requirement for deep mining using a hypothetical case stipulating optimum design criteria for the underground openings. Based on the ventilation requirement, a list of compromises or mitigation measures will be reviewed to improve mine design both from ventilation and a geomechanical point of view. Furthermore, a list of technical and financial impact of the ventilation and geomechanical conciliated design will also be provided.

\section{Introduction}

The demand for minerals is depleting surface deposits. In order to maintain demand, mines must seek resources at greater depths. This implies that geomechanical and ventilation risks must be addressed to maintain safe production. Instinctively, geomechanical constraints could oppose ventilations constraints at greater depth. The use of small openings and placement of infrastructure (shafts and major raises) outside the mining extraction induced stress zone will decrease ventilation efficiency. On the contrary, ventilation and cooling requirements require large openings as close to the workplace as possible. This paper provides some guidelines to conciliate ventilation and geomechanical requirements.

\section{Geomechanical requirements}

Deep mining means increased stress levels which will induce rock mass failure as the extraction of ore increases. Rock mass failure is often associated with the release of seismic energy, large deformation and/or sudden failure known as a rockburst. Therefore, any openings required for ventilation must withstand the changes of mine induced stresses throughout the life of the operation to ensure continuous air flow to the workers and equipment.

Rock mass properties and the in situ stress field are inherent geomechanical constraints that cannot be modified, and they can create the conditions that will induce risk on ventilation infrastructures. Ground support, excavation dimension, and excavation location are the only parameters that can be considered as mitigation measures to minimise geomechanical risks. To illustrate the impact of geomechanical risk on ventilation infrastructures, the following hypothetical cases will be considered:

1. Ventilation design without any geomechanical constraints. 
2. Ventilation design including geomechanical mitigations measures.

General setting of the hypothetical case:

- Depth of orebody: 2,450-2,600 m below surface.

- Within the Canadian Shield (in situ stress listed in Table 1).

- Infrastructure to be developed in footwall granite-gneiss rock mass with properties given in Table 2.

- The ventilation infrastructure requirements are listed in Table 3 (assuming that sufficient air volume is provided from surface down to $2,450 \mathrm{~m}$ ).

Table 1 In situ stress field

\begin{tabular}{ccccc}
\hline Stress & Symbol & Value & Direction & Dip \\
\hline Major principal & $\sigma_{1}$ & $1.8 \times \sigma_{3}$ & East-west & $0^{\circ}$ \\
Intermediate principal & $\sigma_{2}$ & $1.4 \times \sigma_{3}$ & North-south & $0^{\circ}$ \\
Minor principal & $\sigma_{3}$ & $2,700 \mathrm{~kg} / \mathrm{m}^{3} \times \mathrm{g}^{*} \times \mathrm{h}^{*}$ & Vertical & $90^{\circ}$ \\
\hline
\end{tabular}

${ }^{*} \mathrm{~g}$ is the gravity of $9.81 \mathrm{~m} / \mathrm{s}^{2}$.

*h depth in $\mathrm{m}$.

Table 2 Granite-gneiss properties

$\begin{array}{cc}\text { Unconfined compressive strength (MPa) } & 200 \\ \text { Young modulus (GPa) } & 60 \\ \text { Poisson's Ratio } & 0.25 \\ \mathrm{~m}^{*} & 0 \\ \mathrm{~S}^{*} & 0.11 \\ \mathrm{Q}^{\prime} \text { (Barton et al. 1974) } & 5-25\end{array}$

${ }^{*} \mathrm{~m}$ and $\mathrm{S}$ are Hoek and Brown constant for a brittle failure criterion (Hoek \& Brown 1980, 1988; Martin et al. 1999).

Table 3 Ventilation infrastructure requirements

\begin{tabular}{cccc}
\hline Number of raises & Diameter $(\mathrm{m})$ & $\begin{array}{c}\text { Number of } \\
\text { transfer drift }\end{array}$ & $\begin{array}{c}\text { Drift cross-section } \\
\text { width } \times \text { height }(\mathbf{m})\end{array}$ \\
\hline 8 & 5.5 & 8 & $7.6 \times 5.5$ \\
1 & 5 & 1 & $6 \times 6$ \\
7 & 4 & 7 & $5 \times 5$ \\
\hline
\end{tabular}


To illustrate the impact of in situ stress and rock mass properties on the stability of ventilation infrastructure, a two dimension numerical modelling was performed using the Rocscience Phase2D code. The Brittle Failure Criterion (Martin et al. 1999) will be used to analyse the relation between the deviatoric stress and the unconfined compressive strength of the material to establish four damage and failure criteria:

1. $\sigma_{1}-\sigma_{3} \leq 0.3 \sigma_{c}$ : no damage or failure; the rock mass is intact. ( $\sigma_{c}$ is the unconfined compressive strength; $\sigma_{1}$ is the major principal stress and $\sigma_{3}$ is the minor principal stress).

2. $0.3 \sigma_{c}<\sigma_{1}-\sigma_{3} \leq 0.5 \sigma_{c}$ : damage initiation to the rock mass.

3. $0.5 \sigma_{c}<\sigma_{1}-\sigma_{3} \leq 0.7 \sigma_{c}$ : moderate failure of the rock mass with low to moderate seismic activity.

4. $\sigma_{1}-\sigma_{3}>0.7 \sigma_{c}$ : sudden failure of the rock mass with moderate to intense seismic activity.

\section{Ventilation raise}

Figure 1 illustrates the damage zone around a circular raise without support. As expected, due to the depth, the raise will eventually become elliptical in shape as shown. Also notable is the increased failed and damage area around the opening as follows:

- $4 \mathrm{~m}$ diameter raise is surrounded by $18.37 \mathrm{~m}^{2}$ of damaged and failed material.

- $5 \mathrm{~m}$ diameter raise has $31.11 \mathrm{~m}^{2}$ of damaged and failed material. This is an increase of $69 \%$ over the $4 \mathrm{~m}$ diameter raise.

- $5.5 \mathrm{~m}$ diameter raise has $34.23 \mathrm{~m}^{2}$ of damaged and failed material. This is an increase of $10 \%$ over the $5 \mathrm{~m}$ diameter raise and of $86 \%$ more than the $4 \mathrm{~m}$ diameter raise.

This indicates that raw raises are becoming increasingly impractical at depth. The stability of the raise will become compromised over time and the enlargement of the raise may then jeopardise key infrastructures, accesses, or headings, and cause a ventilation restriction due to sloughed material or total failure.

Additionally, large diameter raise bores, driven at depth, with a raise boring machine have a higher risk of being unsuccessful due to ground squeezing of the reamer head as the deformation of the rock mass takes place while boring. Therefore, supported raises are required and the diameter of the raise will have a direct impact on the support cost. As shown in Figure 1, the required support length for the raises with varying diameter will range from $1.8 \mathrm{~m}(0.3 \mathrm{~m}$ of anchorage is assumed beyond the failed rock mass) for the $4 \mathrm{~m}$ diameter raise, to $2.3 \mathrm{~m}$ for the $5 \mathrm{~m}$ and the $5.5 \mathrm{~m}$ diameter raises. They will also need full surface support, e.g. shotcrete and/or screen. The estimated cost per meter to bench down a raise at depth is CAD 14,628 for $4 \mathrm{~m}$ diameter raise, CAD 17,028 for the $5 \mathrm{~m}$ and CAD 18,128 for the $5.5 \mathrm{~m}$ raises. The cost of the raises listed in Table 3 for the $150 \mathrm{~m}$ section of the orebody is about CAD 40,000,000.

Location of the raise is also a key to minimising the impact from the mining induced stresses depending on the orebody geometry and depth. The location of the ventilation raise may be 30-60 $\mathrm{m}$ from the main working, thus increasing capital cost by driving long transfer drifts to provide ventilation where stoping takes place. 


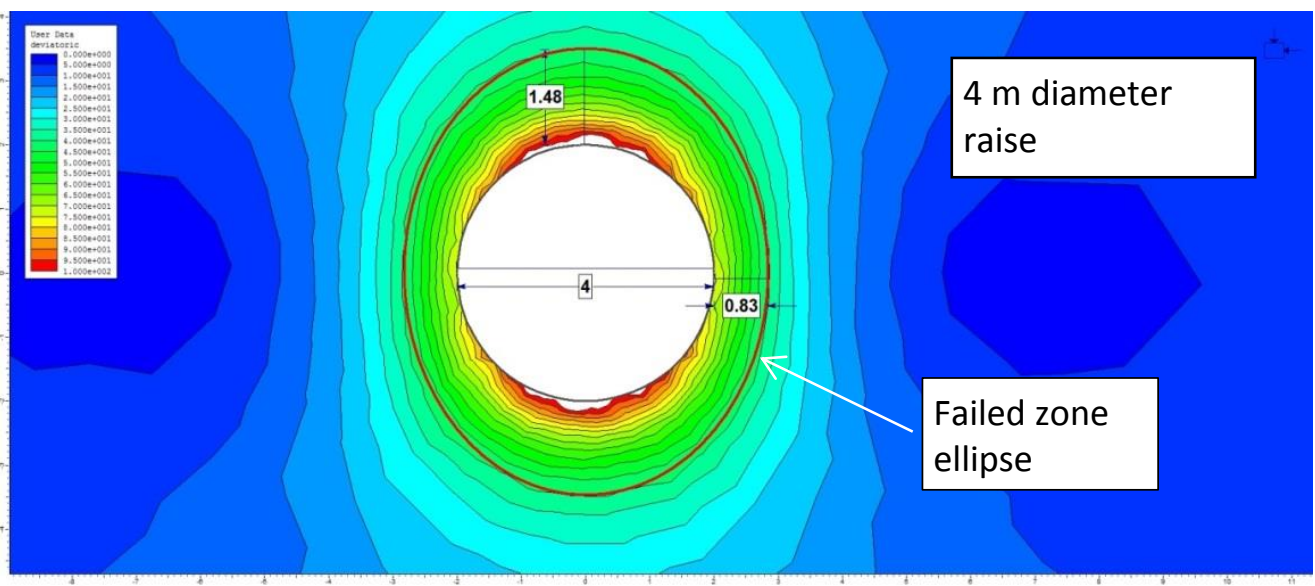

(a)

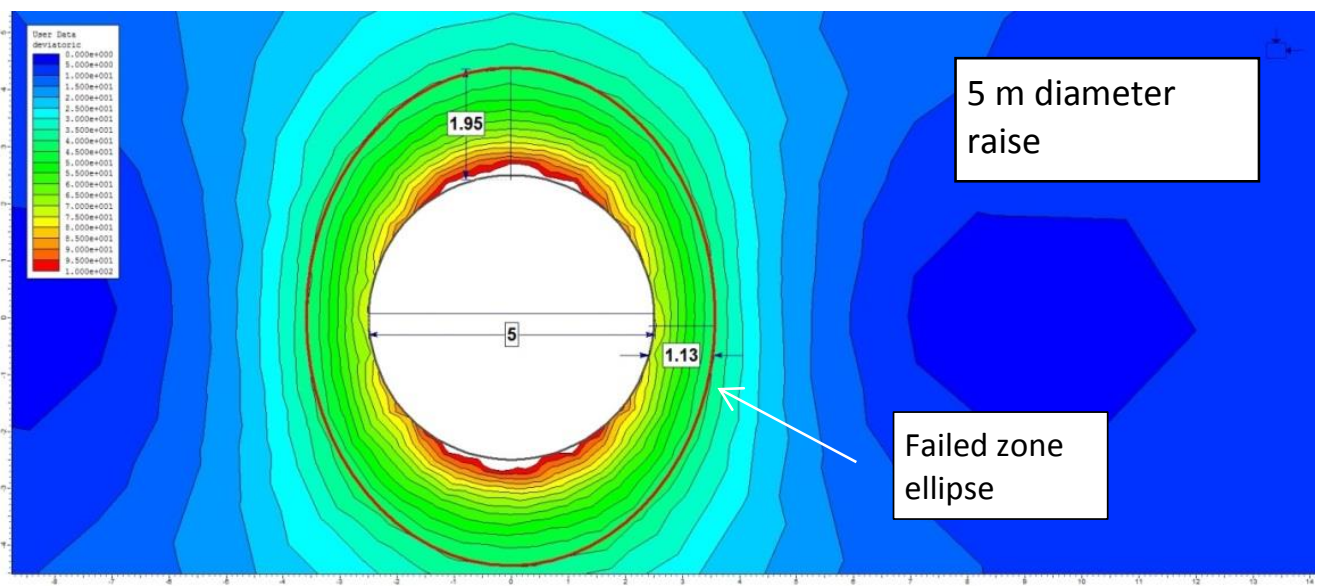

(b)

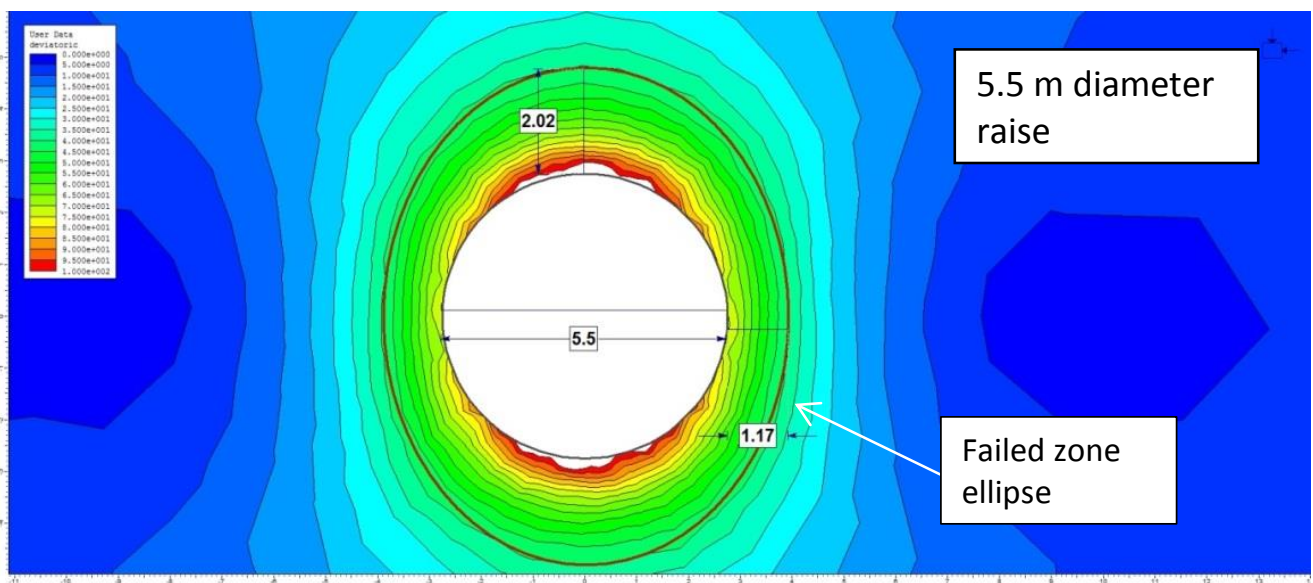

(c)

Figure 1 Damage zone around unsupported raises; (a) $4 \mathrm{~m}$ diameter; (b) $5 \mathrm{~m}$ diameter; (c) 5.5 m diameter

\section{$4 \quad$ Transfer drift}

Figure 2 illustrates the damage zone around two transfer drifts without support. As potentially expected due to the depth, the damage zone is greater than the standard Canadian Shield $1 / 3$ span to estimate length of tendons, and longer support is required to maintain stability. Due to the inherent risk of changing mine induced stresses and depending on the location of the transfer drifts, enhanced support may be required which will increase the cost per meter of drift. For example, the $5 \times 5 \mathrm{~m}$ drift will require $2.3 \mathrm{~m}$ 
long bolt in the back and $0.95 \mathrm{~m}$ long bolts in the walls compared to a $7.6 \times 5.5 \mathrm{~m}$ transfer drift which requires $4.2 \mathrm{~m}$ long bolts in the back and 1.05 long bolts in the wall. The length of the bolt is not the only issue. The increased surface area of the larger drift implies more support and more risk of failure due to changing mine induced stresses. As an approximate overall cost, the first $4.8 \times 4.8 \mathrm{~m}$ transfer drift would cost CAD 4,500 per $m$ to drive and the larger drift will cost up to CAD 6,000 per $m$ to drive. This may require the driving of smaller drift or dual drift with a pillar in between in order to minimise support requirements, and speed the development process and deferred capital investment by driving the second drift at later date. The total cost of the transfer drifts will range between CAD 2,600,000 and CAD 5,200,000, considering that the transfer drift length may vary between 30 and $60 \mathrm{~m}$ depending on the ventilation raises location with respect to the main workings.

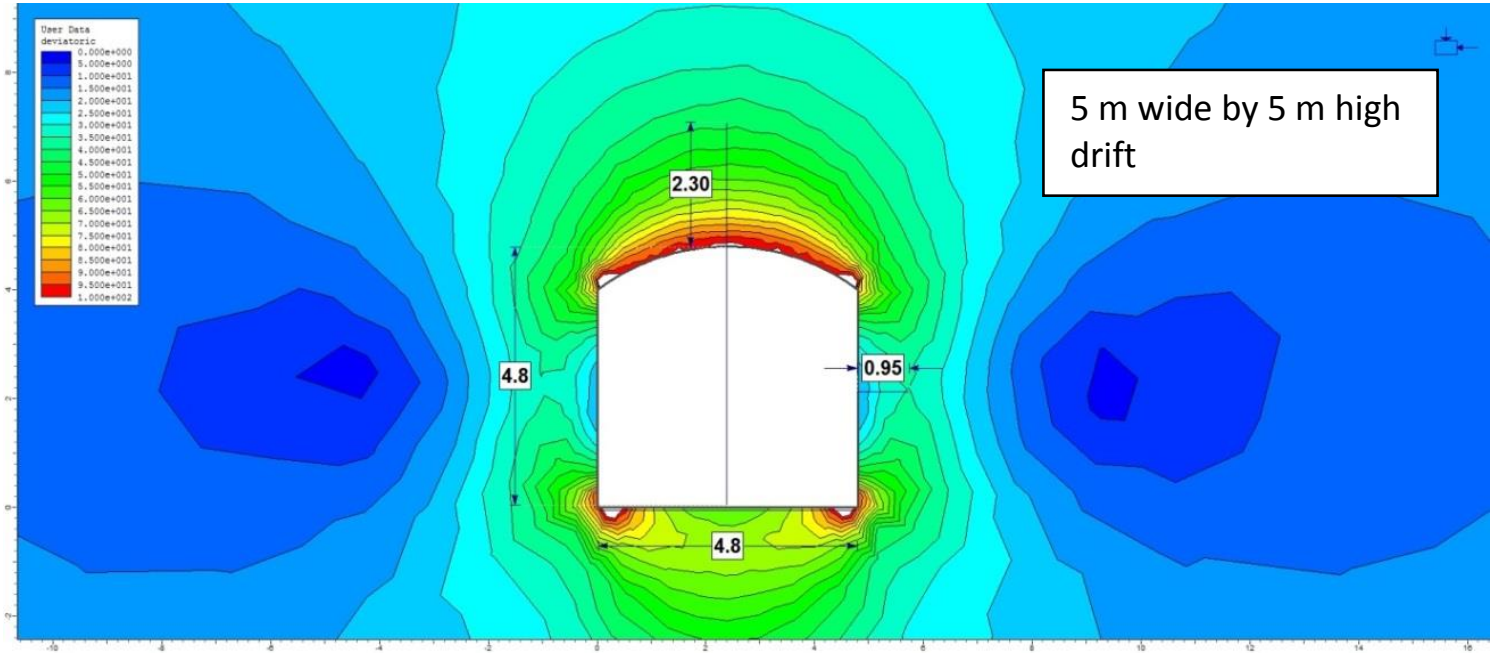

(a)

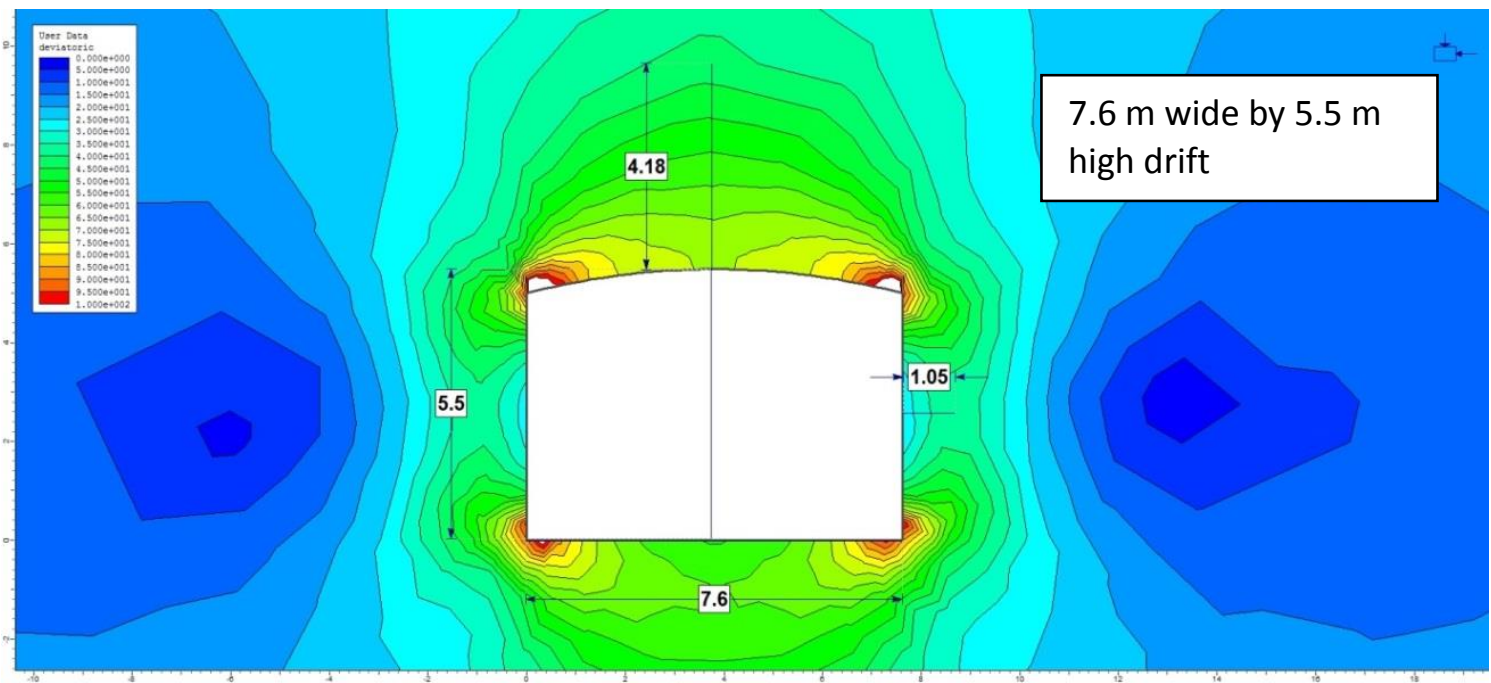

(b)

Figure 2 Damage zone around unsupported transfer drifts; (a) $5 \mathrm{~m}$ wide by $5 \mathrm{~m}$ high drift; (b) $7.6 \mathrm{~m}$ wide by $5.5 \mathrm{~m}$ high drift

\section{$5 \quad$ Ventilation system design (Acuña \& Jodouin 2010)}

In order to ensure good practice in the ventilation design phase of a study, design principles must be established. Best practice mine ventilation system design is based on the following criteria:

- The engineer must consult with local legislation to obtain the most recent requirements that apply. For example, in Ontario, Section 183.1 of Regulation 854 requires that the flow of air must 
be at least $0.06 \mathrm{~m}^{2}$ per second for each kilowatt of power (or $30.58 \mathrm{~m}^{2}$ per minute for each brake horsepower) of the diesel-powered equipment operating in the workplace.

- The engineer must consult with local legislation to obtain the most recent requirements that apply.

- One pass ventilation.

- Direction of airflow within the ramp system must be evaluated in conjunction with ramp access via sublevels and/or shafts.

- Design frictional pressure loss using 249 Pa per $305 \mathrm{~m}$ of airway ( 1 in water gage per $1,000 \mathrm{ft}$.) as a rule-of-thumb for economic airway dimensions.

- Optimum airway velocity limits are to be used for design planning.

- Airflow to garages, lube and fuel bays is required to be exhausted directly into return airways.

- Reject temperatures not to exceed $280^{\circ} \mathrm{C}$ (psychrometric wet bulb).

As part of any mine ventilation system design process, ventilation personnel must first determine the required airflow volume for the life of the mine according to the location of operating equipment and proposed infrastructure facilities. Once the determination of airflow is completed, an initial design can be constructed which is then followed by a review analysis of the initial design to determine any possibilities for improvement.

This analysis consists of optimising the size and shape of airways, the number, location and size of main fans, any ventilation controls (i.e. regulators, doors, etc.) and the performance characteristics of these devices to supply the ventilation requirements at the most efficient cost for the planned operational life of mine. When a mine is designed, the drifts and shafts are sized to accommodate the equipment that is required to travel within them. In most cases this size selection is based on the lowest capital construction cost resulting in minimally sized airways.

Capital cost, however, is only one influential factor in a mine's economic analysis. The designer must also consider the operating cost of infrastructure items. If capital cost is the only consideration for airway size, if not optimised, the result will be higher operating expenditures. This is especially apparent if the expected operational life of the mine is not considered. Such practices can result in a more costly operation and/or eventually to higher capital expenditures due to the requirement for larger fans or ventilation infrastructure upgrades if the airflow requirements increase or as the mine deepens.

Operational costs, associated to the energy required to move the airflow through the mine, can be reduced by increasing the size of the airways. Unfortunately, reducing the operational cost will consequently increase the capital cost as a result of the larger airways. Instinctively, this indicates that an optimal size of an airway exists where there is a balance between the capital cost of construction and operational cost over the operational life of the mine. To avoid airway selection based solely on capital expenditure, an economic analysis, at an early stage in the design process, must be completed. This analysis of the airways is based on capital and energy (operational) cost assuming a fixed airflow volume.

The basis of such an economic analysis can be summarised as follows:

- The airflow volume and the length of the airway are defined.

- Multiple airway sizes are considered with corresponding development costs.

- The operating cost is calculated based on energy demand.

- The net present value (NPV) is then determined for each airway size.

Once the cost of each airway size option is calculated, the minimum combined cost is chosen as the optimal solution, thus, defining the most economic airway size. Based on the results of the analysis, the project team must then select between the initial design size, a smaller or a larger airway. In the case where a 
smaller dimension is recommended by the economic analysis, it is required to investigate if the reduction in airway dimensions will have an impact on the proposed size of the mine equipment. If this is the case, then the recommendation to select a smaller airway should be disregarded.

\section{Context of ventilation design optimisation}

One objective of a ventilation design is to determine the most economical size for primary airways in a mine. Such optimisation processes are mainly motivated to mitigate increased energy expenditures that are generated when an airway has a relatively small section compared to the airflow required within the airway.

The main task is to balance the initial capital cost with the operational cost of the airways through the operational life of the mine. The mine owner's initial incentive is on developing the mine as soon as possible within or under budget with the lowest capital. However, if the analysis is properly developed at an early stage of the mine design, certain airway sizes and configurations can be identified that might not be adequate when considering the overall total cost over the operational life of the mine. It is certain that the initial cost of development could rise when considering the new solution, however, the total costs for the life of mine will be reduced while the same production will be achieved benefiting the company overall.

The adequate size of the airway will be a function of several variables such as:

- Operational life of the mine (years).

- Airflow volume $\left(\mathrm{m}^{3} / \mathrm{s}, \mathrm{kcfm}\right)$.

- Energy cost $(\$ / k W h)$.

- Development cost $(\$ / m, \$ / f t)$.

- Friction factor of the airway $\left(\mathrm{N} . \mathrm{s}^{2} / \mathrm{m}^{4}, \mathrm{lb} \cdot \mathrm{min}^{2} / \mathrm{ft}^{4}\right)$.

- Discount rate used to calculate the discounted cash flow or NPV.

As the capital and operational cost have to be balanced out for the selected alternative, a smaller airway size will be selected under a shorter operational life of the mine, a reduced airflow volume, a reduced energy cost, a more expensive development cost, a smoother or reduced friction factor, and a higher discount rate. On the contrary, if these parameters have the opposite expected value, then the airway selected is expected to have a larger cross sectional area.

Although the capital and energy costs have to be balanced out for the primary airways, there are other costs involved in an analysis. Some of these are the potential fan capital cost reduction and the potential increase of the logistic costs because of a solution that involves different airway sizes and a requirement for different equipment in the mine site. Depending on the depth and extension of the mine and the main ventilation systems, these two variables could play a role in the final decision, but are not considered in this analysis. Nevertheless, they are presented as variables that could be included in future works.

\section{$7 \quad$ Economic analysis methodology}

Past optimisation studies have been developed by several authors for main mine ventilation system designs (Acuña et al. 2010; Calizaya et al. 1987; Huang \& Wang 1993; Lowndes et al. 2005) however, only the proper selection of fans and regulators has been targeted as part of these models. Additionally, some work has been developed to decide where to locate shafts in order to better suit the underground developments and minimize the distances driven by load-haul-dump equipment (Volz et al. 2009). Unfortunately, the proper sizing of drifts, raises and shafts has yet to be developed and integrated into these models, even though they are an important factor that impacts capital and operational costs when deciding the optimal solution for a mine ventilation system design. 
The methodology outlined within this paper describes the application of the classical comparison between the capital cost of developing an airway of a certain size and the operational cost of passing a fixed amount of airflow through that airway. The solution can be shown in graphical or mathematical format and contains the balance between the capital and operational costs that delivers the overall minimum cost. This approach has been previously presented by (Hartman et al. 1997) and (McPherson 1993).

The method illustrated below consisted of building a graph with three curves that represented the relationship between cost and the size of airway selected. An example of this graph is presented in Figure 3.

The first curve represents the capital cost (in blue) associated with the development of the airway which is considered to be the initial cost and put upfront at the beginning of the first period of evaluation. This might not be the case in all underground developments, but it constitutes a conservative approximation for all the cases. As can be observed, the curve increases in terms of cost with the size of the airway; which concludes that the larger the size of the raise the more costly it will be to build it. However, depending on the economies of scale and the equipment available this curve might only be defined for certain sizes of airways and might not be a smooth curve.

\section{Economical analysis}

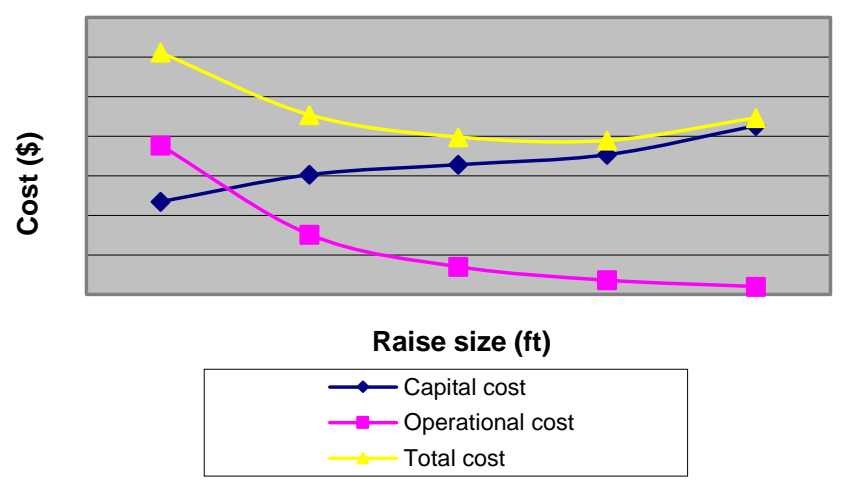

\section{Figure 3 Graphical method curves}

The second curve is the operational cost curve (in purple), which represents the energy cost of providing a fixed amount of airflow through the airway. The operational cost curve decreases as the airway becomes larger because the amount of energy required ventilating the airway is inversely proportional to the size of the airway as stated in the fan laws (Hartman et al. 1997). Each point of the operational curve corresponds to the discounted cash flow or NPV of the energy cost for each airway size through the expected operational life of the mine.

The NPV is a method used to bring the sum of several cash flows in different moments of time, in an equivalent discounted way, to the same initial moment and added to the initial capital cost to generate a valid analysis in terms of which is the economic alternative. For each fixed airway size the energy cost is also fixed because the airflow volume does not vary. This generates what is called an annuity, and because all the cash flows or energy costs are equal, for every period considered, there is a simplified expression to calculate the NPV, as presented in Equation (1).

$$
N P V a=\frac{F}{r} \cdot\left(1-\frac{1}{(1+r)^{n}}\right)
$$

Where, NPVa is the net present value, $F$ is the constant cash flow, $r$ is the discount rate and $n$ is the number of periods (Le Roux 1972).

Finally, the third curve represents the overall or total cost (in yellow) which is the sum of both the capital and operational cost. In Figure 3, it can be clearly observed that the curve defines a parabola with a minimum, which occurs in the airway size of defined diameter. Depending on the significance of the airway in the system as a whole the minimum size of airway that may be considered and the airflow volume 
required, the full shape of the parabola might not be observable in every analysis; nevertheless a minimum will always be identifiable.

\section{Conclusions and further work}

From the experience of previous mine designs, it is not recommended to reduce the size of the primary vertical air routes delivering air to the depths of the mine. Although this may be justifiable for the initial conditions it could eventually result in higher operational costs if the mine requires future expansion necessitating higher air volumes through the mine. Additionally, results from previous economic analysis indicated that the expected improvements are not significant for the deeper raises and are expected to be surpassed by the logistical costs that would be generated.

From the encouraging results obtained and the previous research work developed, a natural step forward will be the integration of the economic analysis methodology with an optimisation methodology that uses a ventilation solver to calculate the airflow volumes in the airways and generate the optimum economic analysis, instead of assuming a fixed airflow. Other variables that could be added are the potential savings in the capital investment for fans and ventilation infrastructure.

From a geomechanical point of view the only mitigation measures available are size of the openings, location of the openings and ground support system. A balance must be reached between optimum ventilation raises size, distance of ventilation raises from the deposit (or stoping area), transfer drifts length and ground support requirement, and the operating cost of the ventilation system. The case study chosen has a capital cost for excavation of the ventilation system ranging between CAD 42,600,000 to CAD 45,200,000 depending on the final location of the ventilation raises with respect to the mine workings.

\section{References}

Acuña, E \& Jodouin, J (2010), 'Optimisation of Upper Kelly Lake Project Ventilation Design', Proceedings of the CIM MEMO Conference and Exhibition, Canadian Institute of Mining, Metallurgy and Petroleum, Westmount.

Acuña, E, Hall, S \& Lowndes, IS 2010, 'Free and semi controlled splitting network optimization using GAs to justify the use of regulators', in R Castro, X Emery \& R Kuyvenhoven (eds), Proceedings of the 4th International Conference on Mining innovation: MININ 2010, Gecamin, Santiago, pp. 79-87.

Barton, NR, Lien, R \& Lunde, J 1974, 'Engineering classification of rock masses for the design of tunnel support', Rock Mechanics, vol. 6, no. 4, pp. 189-239.

Calizaya, F, McPherson, MJ \& Mousset-Jones, P 1987, 'An algorithm for selecting the optimum combination of main and booster fans in underground mines', Proceedings of the 3rd US Mine Ventilation Symposium, Society for Mining, Metallurgy, and Exploration, Englewood, pp. 408-417.

Hartman, HL, Mutmansky, JM, Ramani, RV \& Wang, YJ 1997, 'Economics of Airflow', Mine ventilation and air conditioning, John Wiley \& Sons, New York, pp. 431-451.

Hoek, E \& Brown, ET 1980, 'Empirical Strength Criterion for Rock Masses', Journal of Geotechnical Engineering Division, vol. 106(GT9), pp. 1013-1035.

Hoek, E \& Brown, ET 1988, 'The Hoek-Brown Failure Criterion - a 1988 Update', in JC Curran (ed.), Proceedings of the 15th Canadian Rock Mechanics Symposium, University of Toronto, pp. 31-38.

Huang, C \& Wang, YJ 1993, 'Mine ventilation network optimization using the generalized reduced gradient method', in R Bhaskar, Proceedings of the 6th US Mine Ventilation Symposium, Society for Mining, Metallurgy, and Exploration, Englewood, pp. 153-161.

Le Roux, WL 1972, 'Present values', Mine Ventilation Notes for Beginners, The Mine Ventilation Society of South Africa, Marshalltown, pp. 189-192.

Lowndes, IS, Fogarty, T \& Yang, ZY 2005, 'The application of genetic algorithms to optimize the performance of a mine ventilation network: the influence of coding method and population size', Soft Computing, vol. 9, pp. 493-506.

Martin, CD, Kaiser, PK \& McCreath, DR 1999, 'Hoek-Brown parameters for predicting the depth of brittle failure around tunnels', Canadian Geotechnical Journal, vol. 36, no. 1, pp. 136-151.

McPherson, MJ 1993, 'Ventilation Planning', Subsurface Ventilation and Environmental Engineering, Chapman \& Hall, London, pp. 263-290.

Volz, MG, Brazil, M \& Thomas, DA 2009, 'Strategic optimisation of a vertical hoisting shaft in the Callie underground mine', Proceedings of the Orebody Modelling and Strategic Mine Planning Symposium, in R Dimitrakopoulos (ed.), The Australasian Institute of Mining and Metallurgy, Carlton South, pp. 243-248. 
